\title{
Safety Issues of Biosimilar Products
}

\section{Mohiuddin AK*}

Department of Pharmacy, World University of Bangladesh, Bangladesh

*Corresponding author: Abdul Kader Mohiuddin, Department of Pharmacy, World University of Bangladesh, 151/8, Green Road, Dhanmondi, Dhaka-1205, Bangladesh, Tel: +8801716477485; Email: mohiuddin3@pharmacy.wub.edu.bd

\section{Mini Review \\ Volume 4 Issue 3}

Received Date: July 11, 2019

Published Date: July 18, 2019

DOI: $10.23880 /$ act-16000158

\begin{abstract}
Biosimilars are not expected to be direct copies of biologic medicines and are therefore not the same as generic drugs. Due to the complex structure of biologic medicines and the processes involved in production, biosimilars must be shown on the basis of analytical, non-clinical and clinical data to be similar to an original biologic in terms of structural characteristics, and safety and efficacy. Minor differences with the active ingredient are expected and permitted so long as any such differences are demonstrated not to be clinically meaningful. In $2012,7 \%$ of worldwide sales (US $\$ 53$ billion) were at risk as a result of the free entry of generic drugs, which compete directly with the original brands, forcing them to lower their prices or, even worse, to stop producing them. By 2020, it is expected that this loss of profitability will reach US $\$ 259$ billion. This is clear that biosimilars impose some goods in terms of availability and affordability but surely a discourage to invention of newer biotech products in future.
\end{abstract}

Keywords: Safety Issues; Biosimilar Products; Biotech Products; Inflammatory Diseases

\section{Introduction}

Biologics are complex molecules that are manufactured using living cells and used in the treatment of several chronic inflammatory diseases and cancer [1]. As biosimilars offer the potential for lower acquisition costs versus the originator biologic, evaluating the economic implications of the introduction of biosimilars is of interest [2]. As the costs of biologics are high, biosimilars offer the potential of greater choice and value, increased patient access to treatment, and the potential for improved outcomes [3]. By providing more-affordable treatment options and introducing price competition to the market, biosimilar medicines can generate significant savings. The cumulative savings between 2016 and 2020 in the EU5 and the USA are estimated to range between 49 and 98 billion Euros [4]. The Biologics Price
Competition and Innovation Act (BPCIA) grants 12 years of exclusivity to originator or reference biologics; therefore, by law, the FDA cannot approve a biosimilar until this period has elapsed [2,5]. Patents for many branded biologics will expire during the next few years, allowing biosimilars manufacturers to seek FDA approval for generic versions of these agents [2]. The Biologics Price Competition and Innovation Act (BPCIA), which is part of the Patient Protection and Affordable Care Act, was passed to facilitate the entry of biosimilar drugs into the market [6]. There has been an increasing trend toward the approval of biosimilars in the USA and the EU. The original goal of legislation to approve biosimilars through a fast-track process that would lead to more competition and price reductions is starting to be realized [7]. According to the BPCIA, a biologic product is deemed biosimilar to the already approved, originator biologic if 
the available data show that it is highly similar to the reference product, "notwithstanding minor differences in clinically inactive components, and there are no clinically significant differences between the biologic product and the reference product in terms of safety, purity, and potency of the product" [8-10]. Approval of biosimilars requires comprehensive assessment of all stages of the research and development process, including evaluation of analytical, preclinical and clinical data, to establish biosimilarity to their reference products. The goal of biosimilar comparability studies is not to re-establish efficacy and safety for the proposed biosimilar, but to demonstrate similarity to the reference product $[11,12]$. The biosimilar development pathway consists of a comprehensive comparability exercise between the biosimilar candidate and the reference product, primarily focusing on data from analytical studies. Clinical studies for biosimilar candidates follow a different design to those for a new biological, as the aim is not to independently establish clinical benefit, but to confirm bio-similarity between the two agents [4]. Physician awareness and perceptions towards biosimilars are important factors in their adoption to clinical practice [11]. A biosimilar applicant has to provide a considerably larger package of comparative data than a generic applicant to ensure that the biosimilar can indeed rely, for the purpose of licensing, on the efficacy and safety experience gained with the reference product. While for a generic, the demonstration of similar in vitro dissolution and in vivo bioavailability (so-called bioequivalence) is sufficient to conclude therapeutic equivalence with the reference product, for a biosimilar, comparable physicochemical, biological and functional characteristics as well as efficacy and safety/immunogenicity with the reference product must be demonstrated (Figure 1).

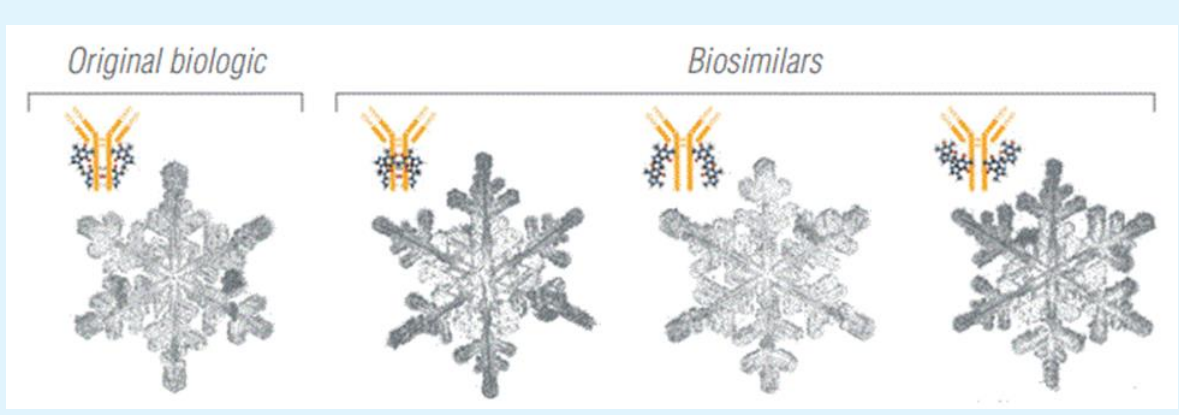

Figure 1: How biosimilars differ from original or Innovator Biologics (Figure adapted from amgem biosimilar report).

In addition, unlike generics, any extrapolation to other indications of the reference product must be scientifically justified [12]. The approval of biosimilars is a highly regulated and detailed process. The European Medicines Agency (EMA) and the US FDA guidance documents stipulate that a biosimilar manufacturer must perform a series of extensive similarity assessments in order to demonstrate bio-similarity to the reference product, and to ultimately gain regulatory approval or licensure [13]. Difference between generic biotech and biosimilar products are: a) Biologic medicines are not made using a set of standard materials, but are developed using unique biological systems and living cells. As a result, the active ingredient is impossible to recreate exactly and the selected cell lines from which the biologic medicine originates are unique to each manufacturer b) The manufacturing process for biologic medicines is generally more complex than manufacturing processes for chemical drugs. Unlike small molecule drugs, biologic medicines are produced in genetically-engineered living cells that are sustained in a highly-controlled environment. The protein produced by the cells will be influenced by individual cell characteristics as well as the environment and nutrients provided c) Each manufacturer has different processes that create distinctive characteristics in the product, which are specific to the manufacturer. This creates a unique relationship between a biologic's manufacturing process and the final product approved by regulators [14-21]. Despite the undeniable advantages of such procedure, some concerns (such as the absence of switching studies or the evaluation of efficacy and safety in all therapeutic indications) still exist about it.

In particular, the European regulatory framework on biosimilars approval does not include the conduction of switching studies demonstrating the interchangeability to be carried out before marketing authorization. This is one of the main aspects that negatively affect healthcare professionals' clinical decisions on switch [22]. The FDA has accepted the concept of extrapolation of indications; 
we just need additional high-quality research on nonmedical switching and the risk of immunogenicity. FDA recently released a white paper indicating the types of trial designs that would be required before nonmedical switching of biosimilars in stable patients could be endorsed-in distinction to substitution by a pharmacist in patients starting therapy. These types of trials would involve multiple crosses between an originator biologic agent and a biosimilar. Thus, we need more studies on switching; especially multiple-switch studies [23-25]. A survey of 470 European physicians belonging to various specialties including rheumatology, nephrology, oncology and dermatology from five European countries (France, Germany, Italy, Spain and the UK) showed insufficient understanding of biosimilar. Only $22 \%$ responded that they were very familiar with biosimilars, and could define what it is. While a majority (54\%) had a basic understanding of biosimilars, $24 \%$ of them answered that they had never heard of biosimilar before. Due to insufficient understanding of biosimilars, half of them thought that biosimilars have to use different International Non-proprietary (INN) Names from the originator biologic agents. However, this understanding of International Non-proprietary Name is misleading and is definitely different from regulatory authorities [26]. Biosimilar market uptake greatly depends on health care provider willingness to promote, prescribe, and use biosimilars in clinical practice.

U.S. and European health care providers still approach biosimilar medicines with caution, citing limited biosimilar knowledge, low prescribing comfort, and safety and efficacy concerns as main deterrents for biosimilar use. To realize the full cost-saving potential of biosimilar medicines, clinician-directed biosimilar education will be imperative to address gaps in biosimilar knowledge, facilitate prescribing changes, and ultimately increase biosimilar use. An overall lack of biosimilar familiarity in U.S. and European health care settings accompanied concerns about biosimilar safety, efficacy, extrapolation, and interchangeability [27]. One of the most significant safety concerns with biosimilars is the potential risk of immune-based adverse reactions. Because of their molecular size, biologics can directly induce anti-drug antibodies which may have significant consequences for both safety and efficacy [28]. Registries should be employed to monitor use of biosimilars and to identify potential adverse effects. The price of biosimilars should be significantly lower than that of reference products to enhance patient access. Bio-mimics are not biosimilars and, if they are to be marketed, they must first be evaluated and approved according to established regulatory pathways for novel biopharmaceuticals [29]. It is important to be clear about whether a specific product has been evaluated through a rigorous evaluation procedure based on the criteria defined in the EMA, FDA, or WHO biosimilar guidelines. It is also important for prescribers to understand what happens when a particular biosimilar receives a designation of 'interchangeable' with the originator and when substitution may occur, as these designations/policies may impact patient outcomes [30].

\section{Acknowledgement}

I'm thankful to Dr. Mamun Rashid, Assistant Professor of Pharmaceutics, Appalachian College of Pharmacy Oakwood, Virginia for his precious time to review my letter to the editor and for his thoughtful suggestions. I'm also grateful to seminar library of Faculty of Pharmacy, University of Dhaka and BANSDOC Library, Bangladesh for providing me books, journal and newsletters.

\section{Financial Disclosure or Funding: N/A}

Conflict of Interest: The author declares that he has no competing interests.

\section{Informed Consent: N/A}

\section{Author Contributions: N/A}

\section{References}

1. Smeeding J, Malone DC, Ramchandani M, Stolshek B, Green L, et al. (2019) Biosimilars: Considerations for Payers. PT 44(2): 54-63.

2. Ventola CL (2018) Biosimilars: part 1: proposed regulatory criteria for FDA approval. PT 38(5): 270287.

3. Patel KB, Arantes LH, Tang WY, Fung S (2018) The role of biosimilars in value-based oncology care. Cancer Manag Res 10: 4591-4602.

4. Barbier L, Declerck P, Simoens S, Neven P, Vulto AG, et al. (2019) The arrival of biosimilar monoclonal antibodies in oncology: clinical studies for trastuzumab biosimilars. Br J Cancer, pp: 1-12.

5. Blackstone EA, Joseph PF (2013) The economics of biosimilars. Am Health Drug Benefits 6(8): 469-78. 


\section{Advances in Clinical Toxicology}

6. Epstein M (2018) Food and Drug Administration guidances on biosimilars: an update for the gastroenterologist. Therap Adv Gastroenterol 11: 17.

7. Burchiel SW, Aspbury R, Munday J (2019) The search for biosimilars and biobetters. Drug Discov Today 24(5): 1087-1091.

8. Calo-Fernandez B, Martinez-Hurtado JL (2012) Biosimilars: company strategies to capture value from the biologics market. Pharmaceuticals (Basel) 5(12): 1393-408.

9. Calvo B, Zuniga L (2012) The US approach to biosimilars: the long-awaited FDA approval pathway. Bio Drugs 26(6): 357-361.

10. Barlas S (2012) FDA Readies New Guidance and User Fee Program for Biosimilars: Drug interchangeability and user fees are contentious issues the FDA must resolve. Is the FDA up to the task? Biotechnol Healthc 9(2): 28-29.

11. Karateev D, Belokoneva N (2019) Evaluation of Physicians Knowledge and Attitudes Towards Biosimilars in Russia and Issues Associated with Their Prescribing. Biomolecules 9(2).

12. Weise M (2019) From bioequivalence to biosimilars: How much do regulators dare? Z Evid Fortbild Qual Gesundhwes 140: 58-62.

13. Kirchhoff CF, Wang XM, Conlon HD, Anderson S, Ryan AM, et al. (2017) Biosimilars: Key regulatory considerations and similarity assessment tools. Biotechnol Bioeng 114(12): 2696-2705.

14. Mark H Lee, Patrick Au, John Hyde, Carmen Gacchina Johnson, Mohammad Heidaran, et al. (2015) Translation of Regenerative Medicine Products Into the Clinic in the United States: FDA Perspective. In: Anthona Atala, et al. Translational Regenerative Medicine, Publisher: Academic Press, pp: 49-74.

15. (2013) Biosimilar Medicines. Pharma Mirror Magazine.

16. (2013) Chapter 2. Biopharmaceuticals are not Chemical Drugs. In: John Geigert. The Challenge of CMC Regulatory Compliance for Biopharmaceuticals and Other Biologics, Publisher: Springer.
17. Chen YC, Yeh MK (2018) Chapter 1. Biopharmaceuticals. In: Chen YC, et al. Biopharmaceuticals, Publisher: Intech Open Limited.

18. (2003) National Research Council (US) Committee on Challenges for the Chemical Sciences in the $21^{\text {st }}$ Century. Beyond the Molecular Frontier: Challenges for Chemistry and Chemical Engineering. Washington (DC): National Academies Press (US); Synthesis and Manufacturing: Creating and Exploiting New Substances and New Transformations.

19. Jacquemart R, Vandersluis $M$, Zhao $M$, Sukhija K, Sidhu N, et al. (2015) A Single-use Strategy to Enable Manufacturing of Affordable Biologics. Comput Struct Biotechnol J 14: 309-318.

20. Chan JCN, Chan ATC (2017) Biologics and biosimilars: what, why and how? ESMO Open 2(1): e000180.

21. Patel PK, King CR, Feldman SR (2015) Biologics and biosimilars. J Dermatolog Treat 26(4): 299-302.

22. Scavone C, Rafaniello C, Berrino L, Rossi F, Capuano A (2017) Strengths, weaknesses and future challenges of biosimilars' development. An opinion on how to improve the knowledge and use of biosimilars in clinical practice. Pharmacol Res 126: 138-142.

23. Feagan B (2017) Benefits, Concerns, and Future Directions of Biosimilars in Inflammatory Bowel Disease. Gastroenterol Hepatol (N Y) 13(12): 745747.

24. Cronstein BN (2015) The benefits and drawbacks of biosimilars. Clin Adv Hematol Oncol 13(10): 639-41.

25. Uhlig T, Goll GL (2017) Reviewing the evidence for biosimilars: key insights, lessons learned and future horizons. Rheumatology (Oxford) 56(suppl_4): iv49iv62.

26. Yoo DH (2014) The rise of biosimilars: potential benefits and drawbacks in rheumatoid arthritis. Expert Rev Clin Immunol 10(8): 981-983.

27. Leonard E, Wascovich M, Oskouei S, Gurz P, Carpenter D (2019) Factors Affecting Health Care Provider Knowledge and Acceptance of Biosimilar Medicines: A Systematic Review. J Manag Care Spec Pharm 25(1): 102-112. 


\section{Advances in Clinical Toxicology}

28. McKinnon R, Ward M (2016) Safety considerations of biosimilars. Aust Prescr 39(6): 188-189.

29. Kowalski SC, Benavides JA, Beltran PA, Roa PAB, Galarza-Maldonado C, et al. (2019) PANLAR consensus statement on biosimilars. Clin Rheumatol 38(5): 1485-1496.
30. Declerck P, Danesi R, Petersel D, Jacobs I (2017) The Language of Biosimilars: Clarification, Definitions, and Regulatory Aspects. Drugs 77(6): 671-677. 